\title{
AMIZADE, PEDAGOGIA E NEOLIBERALISMO: A VERIDICÇÃO NEOLIBERAL E SUAS RESSONÂNCIAS EM UMA AMIZADE PEDAGOGIZADA
}

\author{
Luiz Guilherme Augsburger ${ }^{\mathrm{i}}$ \\ Ana Maria Hoepers Preve $e^{\text {ii }}$
}

\begin{abstract}
Resumo: Neste artigo partimos de dois pontos na relação moderna entre infância e educação para pensar amizade, pedagogia e neoliberalismo. De um lado, o "governo da infância" e suas relações com as práticas pedagógicas sobre indivíduos e populações que, após a segunda guerra, desdobram-se em práticas pedagógicas avaliadas a partir de uma "veridicção neoliberal". De outro lado, temos a emergência de uma amizade entre crianças e a transformação de sua relação com o campo pedagógico: a amizade infantil passa de desencadeadora de problemas a ferramenta pedagógica. A partir disto, mostramos as ressonâncias dessa veridicção neoliberal nessa amizade pedagogizada, lançando mão, sobretudo, de pesquisas na área de educação, infância, neoliberalismo e amizade.
\end{abstract}

Palavras chave: Amizade; Educação; Neoliberalismo; Pedagogia.

\section{AMISTAD, PEDAGOGÍA Y NEOLIBERALISMO: LA VERIDICCIÓN NEOLIBERAL Y SU RESONANCIAS EN UNA AMISTAD PEDAGOGIZADA}

RESUMEN: En este artículo empezamos desde de dos puntos en la relación moderna entre niñez y educación para pensar amistad, pedagía y neoliberalismo. De una parte, el "gobierno de la infancia" y sus relaciones con prácticas pedagógicas sobre individuos y populaciones, que tras la segunda guerra se despliega en prácticas pedagógicas evaluadas desde una "veridicción neoliberal". De otra parte, tenemos el acenso de una amistad entre niños e la transformación de su relación con el campo pedagógico: la amistad infantil se va de desencadenante de problemas hacia una herramienta pedagógica. A partir de esto, enseñamos las resonancias de la veridicción neoliberal en esa amistad pedagogizada, empleando sobre todo investigaciones en el área de educación, niñez, neoliberalismo y amistad.

Palabras clave: Amistad; Educación; Neoliberalismo; Pedagogía.

\section{Introdução}

A invenção da infância, ou pelo menos de uma infância moderna, instituiu consigo uma série de práticas discursivas e não-discursivas no âmbito da educação, entre as quais está o "governo da infância" por meio dos aparatos pedagógicos (KOHAN, 2005; BUJES, 2001). Nos estudos que seguem esse tema da condução da conduta infantil não só se vê a emergência de uma "sensibilidade" em relação à criança (ARIÈS, 1981), como também a elaboração do infante como sujeito e objeto de práticas pedagógicas dentro e fora do espaço escolar - ligadas a uma política sobre a vida, ou como a chamou Michel Foucault (1976), “biopolítica”. O governo da infância nas últimas décadas, por sua vez, vai atualizar seus aparatos e 
estratégias pedagógicos através de uma racionalidade neoliberal, na qual o crivo de "veridicção" de suas práticas educacionais é o sujeito "empreendedor de si” e a lógica de mercado.

Entrementes, esse mesmo acontecimento da infância marcou também a emergência, na modernidade, de uma amizade infantil e, subsequentemente, de efeitos dessa no território pedagógico. Em um primeiro momento, pois, vemos a amizade entre as crianças apresentar-se como um problema no processo de escolarização. Não obstante, atualmente, ela tem passado a aparecer na discursividade pedagógica como elemento a ser considerado em favor da educação da criança. Tendo em vista esse processo de "pedagogização" da amizade infantil e a estreita relação entre os aparatos pedagógicos e a "veridicção" neoliberal, propomos, para este artigo, perseguir a pergunta seguinte: em que medida a pedagogização da amizade (infantil) pode ser lida a partir da veridicção neoliberal? Ou, dito de outro modo, em que medida a mesma lógica neoliberal que anima as práticas biopolíticas atuantes sobre a infância ressoa nas discursividades desse processo em que a amizade infantil passa de um problema a uma ferramenta pedagógica?

Para tanto dividimos este artigo em quatro partes. Na primeira, retomamos sinteticamente as análises presentes em estudos sobre o governo da infância, a biopolítica e, especialmente, o papel de pedra de toque desempenhado aí pela veridicção neoliberal a partir da segunda metade do século XX. Na segunda parte, traçamos o movimento das práticas modernas em torno da amizade entre crianças, sobretudo em seus aspectos educacionais e escolares, fazendo uso de bibliografias sobre o tema, mas também de filmografias que portem essas práticas discursivas. Assim, intentamos mostrar nessa parte uma amizade infantil entanto que desencadeadora de problemas escolares e morais senão ser substituída, ao menos, na atualidade, ser flanqueada por uma amizade enunciada como ferramenta pedagógica. Na terceira parte, cotejamos essas práticas discursivas em que a amizade é "pedagogizada" com a veridicção neoliberal e suas reverberações nos territórios educacionais tratados na primeira parte. Por fim, traçamos algumas considerações finais nas quais tentamos localizar essa análise da amizade pedagogizada e da veridicção neoliberal em um plano mais amplo. Neste sentido, assomam-se à dimensão pedagógica as discursividades da amizade enquanto objeto de uma psicologização e de uma capitalização na contemporaneidade.

\section{Governo da infância, biopolítica e veridicção neoliberal}

O tema da infância na modernidade, segundo aponta Helena Almeida e Silva Sampaio (2019), invariavelmente remete à ideia de "invenção da infância" cunhada por Philippe Ariès (1981). A despeitos da possível "ingenuidade" ou dos equívocos do historiador francês (HEYWOOD, 2004), parece razoável aceitar que na modernidade "surgem uma série de instituições com o objetivo de separar e isolar a criança do mundo adulto, entre elas, a escola" (ARIÈS, 1981, p. 11). Esse gesto moderno, não só indicaria uma 
(nova) sensibilidade em relação à infância como também uma objetivação dela no campo de "saber e poder, no jogo de relações entre o pensamento e a verdade" (KOHAN, 2005, p. 63).

Esse tipo de olhar analítico em que saber, poder e verdade se cruzam para pensar as condições de possibilidade modernas da criança vai amparar-se muito amiúde em estudos de M. Foucault para daí pensar um "governo da infância" (BUJES, 2002; 2008; RESENDE, 2015). O próprio pensador francês, em algumas das aulas de seu curso "Os anormais" (FOUCAULT, 1999), aborda a questão da emergência de práticas (discursivas e não-discursivas) em torno da infância. Ainda que em M. Foucault o tema da infância fora secundário em relação a questões como o saber-poder médico ou o dispositivo da sexualidade, já estavam lançadas as bases para os estudos em que nos são apresentados os aparatos pedagógicos, sobretudo assomados a outras instâncias, para uma análise de um governo de sujeito-criança.

Vemos nessas análises os aparatos pedagógicos, pois, percorrerem territórios distintos e apoiaremse em estratégias e saberes variados a fim de produzir e de governar essa criança moderna. As análises de René Schérer, por exemplo, percorrem a elaboração ilustrada de uma criança "enquanto material humano a ser colocado em reserva, material maleável do homem por vir" (SCHÉRER, 2002, p. 17), bem como uma postura pedagógica na qual a infância converte-se em um espaço-tempo cuidadosamente segregado e “objeto específico de atenção no plano social, [em que] suas tarefas e brincadeiras terão o único objetivo de contribuir para a própria formação [da criança]" (SCHÉRER, 2002, p. 17). O filósofo francês, em seu livro "Emílio pervertido" (SCHÉRER, 2006), trata do "indigesto" tema da sexualidade das crianças, no qual vê não só uma necessidade de negação da sexualidade do infante, por parte dos adultos, como vê nessa prática um ponto fulcral da (trans)formação da criança em um adulto desejável - a uma lógica moral, política e econômica. Ainda que não se paute nos estudos de seu contemporâneo, M. Foucault, (ou que só venha a apropriar-se deles em uma reedição de seu livro), na proposta de R. Schérer reverbera uma problemática muito símil à que encontramos em “Os anormais” (FOUCAULT, 1999) a propósito do onanismo e da pederastia, a saber, o governo da infância (e dos adultos) por meio da sexualidade.

Maria Isabel Edelweiss Bujes (2001) em sua tese doutoral não só traça uma "genealogia" da infância como a aproxima das questões "biopolíticas”. Biopolítica, para M. Foucault (1976, p. 134-5) designa:

o que faz com que a vida e seus mecanismos entrem no domínio dos cálculos explícitos, e faz do poder-saber um agente de transformação da vida humana [e, assim,] um poder que tem a tarefa de se encarregar da vida terá necessidade de mecanismos contínuos, reguladores e corretivos. Já não se trata de pôr a morte em ação no campo da soberania, mas de distribuir os vivos em um domínio de valor e utilidade. Um poder dessa natureza tem de qualificar, medir, avaliar, hierarquizar, mais do que se manifestar em seu fausto mortífero; não tem que traçar a linha que separa os súditos obedientes dos inimigos do soberano, opera distribuições em torno da norma. 
Assim, um poder cuja tônica recai sobre produzir e gerir vidas, mais que as eliminar, tem por mecanismos de governo os cálculos e a norma sobre os sujeitos viventes. A ação desse biopoder sobre os sujeitos faz-se tanto por meio de dispositivos "disciplinares" e sobre "corpos individuais" (FOUCAULT, 1975), quanto por meio de dispositivos "estatísticos" e corpos "populacionais" (FOUCAULT, 2004a; 2004b).

Voltando à análise de M. Bujes (2001), ela indica "Emílio" de Jean-Jacques Rousseau (1966) como uma expressão do nascimento dessa infância moderna e, consequentemente, das discursividades para conduzi-la a horizontes desejáveis. Essa pedagogia cruza tanto elementos disciplinares de elaboração de um corpo produtivo, mensurável e normalizável em nível de indivíduo, quanto o permite conduzir e gerir em nível populacional. A criança se desdobra em um quadrilátero (ou duplamente um duplo): ela é ao mesmo tempo sujeito-objeto/indivíduo-população de práticas de saber-poder.

O governo da infância seria, nesse momento, a condução dessa criança dentro de uma lógica de criação e gestão da vida, de cálculo e normalização dos corpos (individuais e coletivos) e de sua produtividade. Enquanto criança, o sujeito passa a ter sua vida acompanhada e conduzida de modo a chegar a uma vida adulta produtiva. Na criança não está o "germe" do adulto que ela será (mais ou menos invariavelmente), ao contrário, ela é um sujeito/objeto sobre o qual será preciso atuar, um corpo sobre o qual se irá investir para que venha a ser o adulto desejado. Em seu corpo não está inscrito seu ser adulto, é preciso/possível inscrever nele um sujeito governável - por si mesmo e pelos outros, enquanto indivíduo e enquanto população. Os aparatos pedagógicos, então, serão aqueles que se ocuparão desse trabalho, sobretudo, mas não somente, na instituição escolar.

A pensar do caráter "transdiscursivo [...] da pedagogia moderna" de que fala Mariano Narodowski (2001), é na instituição escolar que se vê mais explicitamente como se deu a relação entre infância, poder e o saber pedagógico. É aí que vamos ver aproximarem-se infante e aluno, até uma quase indissociação, por meio do qual a pedagogia vai agir. Ainda segundo M. Narodowski (2001, p. 24),

a Pedagogia, enquanto produção discursiva destinada a normatizar e explicitar a produção de saberes no âmbito educativo-escolar, dedica seus esforços para fazer das crianças "futuros homens de proveito", ou "adaptados à sociedade de maneira criativa", ou "sujeitos críticos e transformadores" etc. A Pedagogia obtém na infância sua escusa irrefutável de intervenção para educar e reeducar na escola, para participar na formação dos seres humanos e dos grupos sociais.

Desta feita, a retórica pedagógica não só aproxima aluno, enquanto sujeito escolar (BELTRÃO, 2000), e criança, enquanto objeto do governo da infância, como vai estipular "os caminhos certos para chegar aos resultados desejados" (NARODOWSKI, 2001, p. 77). Nesse sentido, inclusive, Jorge Ramos do Ó (2003) fala de uma modernidade pedagógica na qual o aluno não só é governável pedagogicamente, mas 
governa a si mesmo nessa lógica.

Tendo em vista a relação entre infância, pedagogia e biopolítica, caberia perguntarmos: Como determinar o que são "resultados desejados”? E qual é esse "sujeito desejável” a que conduz a criança? Para determinar o lugar de "veridicção" - i. e., o lugar que permite verificar/falsificar ou julgar como boa/má uma prática governamental e seus efeitos - da biopolítica, M. Foucault (2004b) vai estudar o liberalismo e o neoliberalismo. É aí onde o pensador francês encontra o mercado como lugar de veridicção e o homo œeconomicus como seu sujeito. E se o autor inicia esses estudos, no curso de 1978, com o liberalismo do século XVIII e XIX, ele vai, no curso de 1979, ao neoliberalismo, especialmente o ordoliberalismo alemão e o anarcoliberalismo estadunidense de meados do século XX, para compreender o lugar de veridicção e o sujeito da biopolítica do pós-guerra. Seguindo essa mesma linha de análise encontramos, em certa medida, no livro "A nova razão do mundo: ensaio sobre a sociedade neoliberal" de Pierre Dardot e Christian Laval (2009) a continuação desses estudos até nossa contemporaneidade. Daí depreende-se que as práticas de governo (biopolíticas) seriam avaliadas segundo uma lógica de/do mercado, segundo um cálculo de utilidade e a partir do homo øeconomicus neoliberal. Teríamos, pois, um jogo de investimentos e rentabilidade como crivo para avaliar, dar continuidade, interromper ou mesmo intensificar as práticas sobre um sujeito que não seria apenas o "sujeito de troca" do liberalismo clássico, mas um sujeito tomado como empresa, um "sujeito empresa de si". As ações desse sujeito e sobre esse sujeito, bem como sobre sua vida, seriam então passíveis de uma avaliação e gestão através dessa mesma veridicção neoliberal.

Encontramos em outra análise de C. Laval (2004) os efeitos dessa veridicção neoliberal no campo escolar. Em um duplo movimento, essa lógica invade a escola e orienta os discursos e práticas pedagógicos e, transbordando o espaço-tempo "escolar", essa pedagogia neoliberalizada passa a transitar por vários setores e instituições sociais. Isso através de um processo que C. Laval (2004, p. X) chamou de "monopolização progressiva pela ideologia neoliberal do discurso e da dinâmica reformadora", com a ressalva de que essa escola neoliberal é antes uma tendência e não uma realidade acabada. Encontramos um olhar semelhante, de uma invasão das palavras empresariais no campo pedagógico, nos últimos textos de Jorge Larrosa $(2016 ; 2018)$ e no livro "Em Defesa da Escola", de Jan Masschelein e Maarten Simons (2014). A colonização da linguagem educacional pelo discurso empresarial tornaria inviável pronunciar e pensar as práticas pedagógicas sem passar por ideias, como "meta", "qualidade", "eficiência" etc., que conformam as possibilidades do campo educacional à lógica de um "capitalismo cognitivo".

Neste ínterim, não só a lógica de mercado e o sujeito empresa de si passam a fazer parte das práticas pedagógicas como também uma discursividade relacionado ao campo psicológico vai assomar-se. Por meio desses saberes, conceitos como "habilidades" ou "competências" (skills) psicologizam a pedagogia e a tornam veridizível em termos neoliberais (MASSCHLEIN, SIMONS, 2014). Aqui poderíamos dirigir-nos a outra pesquisa de M. Bujes (2002), na qual ela analisa a invenção do "eu infantil" como uma mise en 
œuvre dos dispositivos pedagógicos. Em uma mais recente análise da pesquisadora sobre a pedagogia reggio-emiliana, ela não só aponta o governo da infância por meio dessa pedagogia marcadamente alternativa à pedagogia tradicional, como percebe nela os efeitos de como "a Psicologia colonizou nossos modos de pensar, descrever e construir os modos de ser criança” (BUJES, 2008, p. 118).

Sylvio de Souza Gadelha (2010), em seu texto "Governamentalidade neoliberal e instituição de uma infância empreendedora", traz essa governamentalidade neoliberal como instituinte de uma infância empreendedora através de práticas pedagógicas. Nessas práticas, por sua vez, o que está em jogo é o desenvolvimento e a aprendizagem de habilidades cognitivas e socioemocionais dentro de uma linguagem em que criança e educação se convertem em investimentos - dos pais, do Estado, da sociedade. Não só o sujeito é alvo dessas práticas, como há uma ação sobre seu meio, para que esse favoreça as práticas de investimento, concorrência, desenvolvimento de habilidades etc. Os efeitos dessa neoliberalização da educação expressam-se também no que Mirele Corrêa (2017) coloca enquanto um "corpo-performático" sendo produzido no ambiente escolar, a partir da ideia de "cultura performática", desenvolvida por Stephen Ball (2010), proveniente das políticas públicas. Esse corpo-performático é visível, amiúde, em práticas discursivas e não-discursivas já subjetivadas pelos próprios alunos. Nas palavras de S. Gadelha (2015, p. 351): "toda conduta individual, que responde de forma sistemática a modificações nas variáveis do meio, sendo esse meio entendido como o mercado, como a realidade econômica, deve referir-se a uma análise de tipo econômica". Outra vez, é uma análise econômica que torna inteligível a conduta de um sujeito inserido em um meio, esse também pensado dentro dessa lógica neoliberal. Se pensamos nesse meio, em termos pedagógicos, como sendo a escola, retornamos à análise de C. Laval (2004) em que a escola e os sujeitos dentro dela são lidos (e "geridos") como uma empresa.

Até aqui, pois, tentamos traçar os contornos em que o governo da infância, em conjunção com um saber-poder pedagógico, elabora e conduz a criança a um horizonte desejável. A esse sujeito infantil que desde uma governamentalidade biopolítica e neoliberal -analogicamente ao homo oeconomicus poderíamos chamar de "puer aeconomicus": uma criança que não só é inventada, que não só ganha tempos, espaços e saberes particularizados, mas que terá sua vida subjetivada e objetivada desde uma lógica empresarial. O que trataremos doravante, então, são as relações da infância, especialmente enquanto sujeito de governo, com as práticas de amizade.

\section{Amizade infantil e pedagogização da amizade}

Quando olhamos os trabalhos sobre a história da amizade, a amizade entre crianças não só tem uma forma específica na modernidade, como parece ter (só) aí suas condições (mais ou menos) gerias de possibilidade. Nas genealogias da amizade de Francisco Ortega (2002), o amigo infante não é uma figura 
da amizade cavalheiresca que se elogia no romance cortês, como também não é discutida nos textos cristãos medievos e de fins do império romano. Como muito, poderíamos localizar algo nas discussões da Grécia clássica, e. g., o diálogo platônico "Lísis” (PLATÃO, 1925). Nesse diálogo, Sócrates interpela Menexeno e Lísis, dois "garotos" ( $\pi \alpha l \delta i \alpha ́$ - paidiá), sobre sua "amizade" ( $\varphi \imath \lambda i \alpha$ - philia). Entretanto, não só seria anacrônico traduzir "paidiá" por "crianças", também o seria a tradução de "philia" por "amizade". David Konstan (1997) observa que a palavra "philia" tinha na Grécia clássica um alcance mais próximo da palavra atual "amor" do que da "amizade". "Philia" não designava a relação entre "amigos" ( $\varphi$ í tinha uma tal amplitude que se poderia expressar outros amores (e. g., o amor parental, amor conjugal ou mesmo relações entre cidadãos). As especificidades da relação, então, eram dadas, como vemos em Aristóteles (1934) na "amizade entre amigos", na qual havia uma hegemonia discursiva sobre a relação entre homens, bem como eram só os adultos livres que eram capazes de uma "verdadeira amizade", ou de uma philia em que se poderia amar o outro em sua virtude. Essa ideia que liga amizade verdadeira e vida virtuosa perpassa praticamente toda a filosofia clássica, helenística e romana (KONSTAN, 1997; FRAISSE, 2016). Ainda que houvesse nos textos filosóficos desses períodos sobre amizade importantes discussões sobre seu papel na formação dos sujeitos, ao pautarem-se numa relação entre sujeitos virtuosos, elas acabavam por (praticamente) excluir a possibilidade de uma (verdadeira) amizade entre paidiá ou, nos textos latinos, pueri. Isto porque a "amizade entre amigos" pressupunha um grau de igualdade entre os sujeitos (KONSTAN, 1997), enquanto a relação (formadora) dos jovens com sujeitos virtuosos dava-se com o professor ou mestre e, portanto, para pensadores gregos e romanos, era desigual. Isto porque a vida adulta e virtuosa estava marcada por um corte em relação à juventude, não apenas por corte etário, mas de papéis, o jovem, sobretudo enquanto aluno ou discípulo, mantinha um caráter de passividade, enquanto a vida adulta, especialmente do cidadão livre, era marcada por seu caráter de atividade (FRAISSE, 2016).

Ao dar à infância um espaço-tempo próprio, com outros vínculos em relação à vida adulta, a modernidade instaura condições para uma discursividade onde não só haveria uma amizade possível ou mesmo própria às crianças, com uma discursividade em que a amizade (ou ao menos certas amizades) converte-se em fenômeno infantil, como indica o texto de Maurice Aymard (2009). Com o advento da sociedade burguesa, sua intimidade e, posteriormente, do matrimônio e da sexualidade vitorianos, a amizade prolongada entre adultos pôde configurar-se como "suspeita". Especialmente quando não secundária em relação ao amor conjugal, ela passa a ser vista com certa desconfiança que, ligada aos "perigos" da homossexualidade, se desdobra em regulações quanto à conduta amical e à intimidade entre adultos. Essa suspeita quanto à amizade adulta aparece já em fins do século XVIII para a relação entre homens (ORTEGA, 2002; AYMARD, 2009), sendo mais tardia nas relações entre mulheres (FADERMAN, 2001). Lilian Faderman (2001) reporta o espanto de viajantes europeus em fins do século XIX frente às condutas amicais femininas nos Estados Unidos. Contudo, na segunda metade do século XX, as amizades 
entre mulheres, mesmo no Novo Mundo, tornam-se também passíveis dos cuidados e regulações da intimidade derivados dessa amizade prolongada e da homossexualidade (FADERMAN, 2001, ORTEGA, 2002).

Esse acontecimento e, em certo sentido, privilégio da "amizade infantil" não significa, entretanto, que ela estava livre de regulações ou desconfianças, haja vista todo o aparato de governo da infância que apresentamos anteriormente. Não seria espantoso, portanto, que a amizade entre crianças constitua uma problemática política e pedagógica. Nesse sentido, o cuidado com a companhia da criança em "Emílio" (1966) ou em "Nova Heloisa" (1843) de J-J. Rousseau seriam exemplos desse acontecimento, onde certos riscos da amizade já estariam presentes como tema pedagógico. Porém, a forma como a amizade infantil aparece no território da educação escolar parece-nos exemplar, também, em alguns filmes - dos quais, neste artigo, exploremos três: “Zero em Comportamento" (ZÉRO, 1933); “Os esquecidos” (LOS OLVIDADOS, 1950) e "Os incompreendidos" (LES QUATRE, 1959).

Na trama de "Zero em Comportamento" (ZÉRO, 1933), de Jean Vigo, as crianças de um internato vão constituindo suas amizades e relações de proximidade como parte chave à elaboração e execução de uma revolta contra a escola. Há uma série de cumplicidades e gestos de cuidado que lhes permite resistir ao aparato pedagógico - seja um chocolate que se reparte, um segredo que se guarda, seja ainda um momento de constrangimento ou acosso público do outro que o amigo que faz parar. Do ponto de vista dos adultos, há duas cenas emblemáticas em que é flagrante o olhar de suspeita e periculosidade da relação amical entre dois personagens. Na primeira temos uma conversa entre o inspetor-geral e o diretor que, ao verem os dois meninos passarem abraçados sob um casaco para protegerem-se da chuva, concluem que a "amizade se tornou excessiva" e que os garotos "precisam ser vigiados". Na segunda cena, o diretor conversa com o mais novo e "sensível" dos garotos, advertindo-o dos riscos de tal amizade, uma vez que o outro amigo teria uma personalidade “neuropática, psicopática e Deus sabe mais o que!” (ZÉRO, 1933). Além das suspeitas da proximidade entre os dois garotos, a amizade torna-se perigosa, no filme, na medida em que leva um garoto tímido à comportamentos cada vez mais indisciplinados, culminando com sua participação na organização do motim infantil.

No filme de Luis Buñuel de 1950, "Os Esquecidos" (LOS OLVIDADOS, 1950), a amizade entre crianças pobres se dá praticamente na rua e sob um espectro de delinquência - ainda que tenhamos a nítida sensação de que essa conduta transgressora é mais uma fatalidade do que uma escolha dos sujeitos. Por conta dessa condição, a mãe de um dos meninos protagonistas, após a acusação de o filho haver cometido um crime, pede às autoridades que o enviem a um reformatório. Na breve passagem pela instituição - nesse filme, a encarnação mais evidente dos aparos pedagógicos e/ou disciplinares -, não vemos a amizade infantil como aquilo que acolhe o garoto ou o leva a permanecer naquele espaço, ao contrário, as amizades parecem fazer força no sentido de levá-lo outra vez à rua e à delinquência. A aparição dos mecanismos 
pedagógicos é secundária no filme, todavia fica latente a relação entre essa ausência "pedagógica" e a presença dessa "amizade delinquente".

No terceiro filme que elegemos, "Os incompreendidos” (LES QUATRE, 1959), por sua vez, deixa explícita a tensão entre o funcionamento da instituição escolar e a relação de amizade entre o personagem principal e seu amigo. A amizade dos dois garotos, que partilham a mesma sala de aula em uma escola, contrasta a todo o tempo com a figura do professor disciplinador. Cada gesto de punição ou reprimenda para imediatamente acompanhado de um ato de indisciplina: gazear aula para ir ao cinema ou jogar fliperama após um castigo do professor em sala ou uma tarefa extra para o dia seguinte; falsificar a assinatura dos pais ou mentir a morte da mãe para justificar a ausência em aula. Porém a tensão entre pedagogia e amizade não é apenas da ordem da indisciplina que busca a diversão, a certa altura da trama, um amigo ajudará ao outro a fugir de casa, a viver longe dos pais, ou a cometer pequenos delitos. Quando um dos garotos é preso por delinquência e enviado ao reformatório, o antigo amigo e as novas amizades em contraste com a visita da mãe, que tenta conformá-lo ao lugar - o auxiliam a resistir ao funcionamento (ainda mais rígido e pedagógico) da instituição e, posteriormente, elas animam-no a fugir dali, ainda que seja uma fuga em que - semelhantemente à do final de "Zero de Comportamento" (ZÉRO, 1933) - ressoa um falta de perspectiva de futuro.

Nesses filmes, mutatis mutandis, fica evidente a tensão entre a amizade das crianças e as práticas pedagógicas de governo da infância, sobretudo da escola. A amizade infantil, então, é retratada como um problema para a elaboração de um sujeito disciplinado inserido em uma população normalizada. Entretanto, essa imagem contrasta com o que encontramos em pesquisas e escritos pedagógicos a partir do começo dos anos 1990. Ora, haja vista as transformações contemporâneas na relação com o par "infância-criança" (SAMPAIO, 2019), não nos deveria estupefazer uma transformação na relação pedagógica com a amizade. Se antes ela parece olhada desde uma desconfiança ou desprezo pedagógico, agora a amizade goza de outras possibilidades veridiccionais (e educacionais). Entre os artigos da área da educação sobre o tema da amizade, não são raras as pesquisas que trazem a amizade para uma dimensão pedagógica. Um material que nos parece exemplar nesse sentido é a síntese de outros trabalhos da área (HARTUP; MOORE, 1990; KATZ; MCCLELLAN, 1191; LADD, 1990) feita por Willard W. Hartup (1992).

Nesse "digest" encontramos a amizade aproximada de uma psicopedagogia, onde se avaliam as "condições da amizade" em termos de autorrevelação (self-disclosure) ou de exposição da intimidade do "eu"; e também onde são apresentadas as "funções da amizade" em "contextos de educação", pensado no "desenvolvimento social da criança" e em seu "ajuste à escola". As funções (pedagógicas) da amizade elencadas nesse artigo são as seguintes: "recurso emocional e cognitivo" (emotional and cognitive resource); tutoria, colaboração e modelagem entre pares (peer tutoring, collaboration and modeling); aprendizagem cooperativa (cooperative learning); e base para as relações subsequentes. 
A semelhança aqui entre as palavras presentes na descrição das funções da amizade e aquelas utilizadas nas pedagogias contemporâneas, mormente as mais inovadoras, é evidente. A semelhança prossegue, e. g., quando W. Hartup (1992, p. 2-3) descrê que os amigos são:

recursos emocionais, tanto por se divertirem quanto por adaptar ante o estresse; recursos cognitivos para a aquisição de conhecimento e capacidade solução de problemas; contextos em que competências sociais básicas (por exemplo, comunicação social, cooperação e habilidade para entrada em grupos) são adquiridas ou elaboradas; e precursoras de relações subsequentes.

Temos aí uma amizade pautada sobre palavras como "diversão", "adaptação", "estresse”, "recursos cognitivos", "capacidades", "solução de problemas", “competências", e mesmo "resultados de desenvolvimento" (developmental outcomes). Essas palavras parecem penetrar o discurso amical de modo símil àquele que J. Larrosa (2018) e Gert Biesta (2017) apontam no campo do discurso pedagógico em geral - seja nos programas governamentais de educação inovadora (CORRÊA, 2017), seja nas pedagogias alternativas (BUJES, 2008).

Esse processo que chamamos de "pedagogização da amizade" dá-se pela inserção da amizade naquilo que concerna a educação das crianças e jovens de 'outros modos', ou não escolares, stricto sensu. A relação entre amizade e aprendizagem é tematizada, e. g., no conteúdo do livro didático, da disciplina de História, para o quinto ano do ensino fundamental. Em um capítulo sobre a história da educação desse livro, encontramos um texto intitulado "Aprendendo com os amigos" (VESENTINI et. al., 2011, p. 29), em que se indicam brincadeiras - viz.: pular corda, amarelinha, futebol - aprendidas com os amigos, fora e/ou antes da escola. Por sua vez, é na escola que se aprende que esse aprendizado por meio da amizade acontece.

Para além dessa retórica da amizade educativa direcionada ao aluno, em artigos acadêmicos como o de Luciana Gruppelli Loponte (2009), encontramos reflexões mais elaboradas sobre o papel da amizade no exercício (ético-estético) da docência. Ou ainda, em outros textos, a amizade entre os alunos é posta como um elemento a que os professores devem estar atentos, uma vez que poderiam funcionar como auxiliadores (ou mesmo peças fundamentais) para lidar com questões pedagógicas como a inclusão e o rendimento escolar (LUQUE PARRA; LUQUE ROJAS, 2015).

\section{Amizade pedagogizada e veridicção neoliberal}

Gostaríamos agora de cotejar essa amizade pedagogizada, que acabamos de apresentar, com aquilo que anteriormente chamamos de veridicção neoliberal, mormente dentro do escopo de suas reverberações nos territórios educacionais. Retomemos, pois, o tema da veridicção. Segundo Foucault (2004b, p. 38) um "regime de veridicção" é o que, em dado contexto "permitiu dizer como verdadeiras e de afirmar como 
verdadeiras um certo número de coisas". Em uma governamentalidade neoliberal, funciona uma "razão de Estado ou essa razão do menor Estado que encontra no mercado sua veridicção se baseia" (FOUCAULT, 2004b, p. 55), o mercado (ou ao menos sua lógica) é o lugar a partir do qual se poderá avaliar como úteis, eficientes ou boas as práticas dessa governamentalidade. $\mathrm{O}$ sujeito dessa veridicção seria, pois, o homo œconomicus, que "não é o homem de troca, não é o homem consumidor, [mas sim] o homem da empresa e da produção" (FOUCAULT, 2004b, p. 152)

Nos territórios educacionais, essa veridicção através do mercado aparece como orientadora das práticas pedagógicas, permitindo avaliar suas estratégias e resultados e compondo sua forma de enunciar as verdades pedagógicas. Desta forma, das políticas públicas mais inovadoras (CORRÊA, 2017) às teorias pedagógicas mais 'alternativas' (BUJES, 2008), vemos a educação engajada no governo dos corpos e na regulação do "meio" (ou "ambiente") para a formação de um sujeito "empresa de si", uma infância empreendedora (GADELHA; 2010; 2015). Não percamos de vista, todavia, em que pese ao transbordamento dessa pedagogia empresarial ao longo do corpo social, que um de seus principais sujeitosobjetos segue sendo a criança, bem como o aluno. E é em relação a esse objeto que o acontecimento de conversão da amizade infantil em ferramenta pedagógica, que chamamos de pedagogização, parece instalar-se (e ser atuante). Essa conversão do lugar da amizade nas práticas pedagógicas, discursivas e nãodiscursivas, faz com que a amizade passe de uma relação predominantemente geradora de problema de indisciplina e improdutividade para uma possível ferramenta ou estratégia de "aprendizagem" escolar.

Se seguimos, então, G. Biesta (2017), vemos as transformações que ocorrem na educação quando sua tônica recai sobre a ideia de aprendizagem; assim, além de transpor o foco do professor ou do saber para o aluno, ela torna o processo mensurável a uma lógica de mercado, convertendo professor e escola em prestadores de serviço e a família e aluno em clientes. A aprendizagem, junto com a ideia de habilidades/competências (socioemocionais), permite que o fazer pedagógico seja avaliável desde uma lógica de rentabilidade e eficiência (BIESTA, 2017), no que podemos ver a ressonância da "veridicção neoliberal" (FOUCAULT, 2004b). As ideias, entrementes, de que amizade atua (positivamente) no "rendimento escolar" (LUQUE PARRA; LUQUE ROJAS, 2015) e de que produz efeitos sobre os "resultados de desenvolvimento" da criança (HARTUP, 1992) não só estariam em consonância com essa educação pautada na aprendizagem de que fala G. Biesta (2017), como fá-la legível como parte da formação de um sujeito capaz de desenvoltura nos meandros socioeconômicos. Afinal, ela tem funções, segundo estudos como os de W. Hartup e Shirley G. Moore (1990; HARTUP, 1992), no desenvolvimento de "recursos emocional e cognitivo", não apenas no trabalho, mas outrossim na "tutoria, colaboração e modelagem entre pares" e permite uma "aprendizagem cooperativa". E como tal, ela torna-se base para as relações subsequentes, daí a importância pedagógica dessa relação: agir sobre ela é produzir efeitos sobre o que a criança será quando adulta. Obviamente, não se trata de um cuidado "arendtiano" (ARENDT, 2006) 
sobre as gerações futuras, entendidas como renovadoras do mundo, e sim de uma hábil modelagem de uma criança em um adulto que saiba mover-se e governar-se em um mundo de competências, investimentos, adaptações, criatividade e inovação. Não parece exagerado, destarte, enxergar nessa pedagogização da amizade ressonâncias de uma pedagogia que leva do puer ao homo æeconomicus.

Pesquisas como as de Lilian G. Katz e Diane E. McClellan (1991) vão, por sua vez, apontar o papel do professor nesse desenvolvimento social de crianças por meio da amizade, ou como as de Gary W. Ladd (1990) em que o professor se coloca como tendo um lugar no processo dos alunos "terem, fazerem e manterem amigos e serem apreciados pelos pares em sala de aula”. Em ambos os casos, similar ao que diz M. Foucault (2004b) sobre a governamentalidade neoliberal e S. Gadelha (2010; 2015) sobre certas práticas pedagógicas contemporâneas, a atuação do professor não se dá diretamente sobre os agentes, como tampouco busca conformá-los a um modelo ideal. O que vemos é antes uma ação sobre o "meio" para que se produza um ambiente propício ao desenvolvimento de um sujeito capaz de regular a si mesmo e avaliar os efeitos de sua conduta através de um crivo (explícita ou implicitamente) "mercadológico". Em outras palavras, a despeito das intenções das autoras ou autores, a discursividade amical presente aí parece-nos indicar a amizade pensada como meio em que a criança possa desenvolver-se dentro de uma lógica (direta ou indireta, explicita ou implicitamente) empresarial.

\section{Considerações finais}

Como considerações finais nos parece relevante assinalar que essa "biopolítica neoliberal" que passa a veridizer as práticas em que se cruzam amizade e pedagogia, também parece ressoar de outras formas na amizade. Isso aparece especialmente no que, seguindo a ideia de "pedagogização", podemos chamar - ainda que muito provisoriamente - de psicologização e capitalização da amizade. Cada qual com suas tensões próprias e elementos particulares, mas também reverberando sobre o campo da educação (AUGSBURGER, 2017).

De forma breve, a amizade "psicologizada" seria marcada por um discurso do sentimento, da interiorização (eu, ego, self etc.) e da clínica (ou da saúde psíquica). Há toda uma preocupação desses saberes em torno do psíquico na constituição de um sujeito "saudável", munido de "competências socioemocionais", na qual a amizade o produz e se produz por tais competências, o que, amiúde, designaria uma amizade gerível dentro da fluidez e desterritorialidade neoliberal (MUÑOZ, 2010; SOUZA; SEDIYAMA, 2012). O que, por sua vez, concorreria para a formação de um sujeito pedagogizado e pedagogizável (AUGSBURGER, 2017). A capitalização da amizade, talvez a face mais explicitamente neoliberal das relações amicais, implicaria as noções de "investimento", "concorrência" e "ethos empresarial", em detrimento de uma moralidade amical tão presente ao longo da história - há toda uma 
“pragmática do mercado" que recobre essa "ética da amizade" (BARON, 1997; SOUZA; GARCIA, 2008). As amizades passam a ter valor e significado a partir de um cálculo de investimento, sobretudo, em si (AUGSBURGER, 2017; MIZOGUCHI, 2016). Aspectos esses que ainda precisariam ser aprofundados e em outros estudos, separadamente e em relação mais estreita com o campo da educação.

Essa multiplicidade amical contemporânea daria forma a um território contemporâneo no qual elas não se sucederiam, alternariam ou mesmo se justaporiam, mas antes teriam uma relação de sobreposição. Desse modo, elas coabitariam nossas práticas de veridicção, objetivação e subjetivação da amizade e da existência. Elas comporiam um mesmo plano de consistência em que eletividade, intimidade e confiabilidade seriam as palavras-chave de uma verdadeira amizade. Fora desse plano de veridicção e governamentalidade neoliberal quiçá essas características não teriam a mesma agência e eficiência sobre os corpos e sobre a vida dos sujeitos amigos. Deste modo, não obstante as amizades contemporâneas tenham certo grau de independência em relação à veridicção neoliberal - ainda que tenha regras próprias de inclusão-exclusão, legitimidade-ilegitimidade -, sacá-las do modo de governação neoliberal e seus processos de subjetivação seria traçar apenas parcialmente o lugar e os efeitos da amizade na contemporaneidade, especialmente seus efeitos pedagógicos sobre a formação do sujeito aos horizontes desejáveis.

\section{Referências}

ARENDT, Hannah. Between Past and Future: eight execises in political thought. New York/US: Penguin Books, 2006.

ARIÈS, Philippe. História Social da Criança e da Família. 2. ed. Rio de Janeiro: LTC, 1981.

ARISTÓTELES. The Nicomachean Ethics. London: William Heinemann Ltd., 1934

AUGSBURGER, Luiz Guilherme. Que pode a amizade?: movimentos cartográficos e educação em terras de clausura. 2017. Dissertação (Mestrado em Educação) - Faculdade de Ciências Humanas e da Educação, Universidade do Estado de Santa Catarina, Florianópolis, 2017.

AYMARD, Maurice. Amizade e convivialidade. In: CHARTIER, Roger (org.). História da vida privada, 3: da Renascença ao Século das Luzes. Tradução de Hildegar Feist. São Paulo: Companhia das Letras, 2009. p.439-81.

BALL, Stephen. J. Profissionalismo, Gerencialismo. Performatividades e fabricações na economia educacional: rumo a uma sociedade performativa. Educação e realidade, v. 35, n. 2, 2010, p. 37-55.

BARON, Gerald R. Friendship marketing: growing your business by cultivating strategic relationships. Grant Pass, OR: The Oasis Press/PSI Research, 1997.

BELTRÃO, Ierecê Rego. Corpos dóceis, mentes vazias, corações frios. Didática: o discurso científico do disciplinamento. São Paulo: Imaginário, 2000.

BIESTA, Gert. Para além da aprendizagem: educação democrática para um futuro humano. 1. ed. Belo Horizonte: Autêntica, 2017. 
BUJES, Maria Isabel Edelweiss. Infância e maquinarias. 2001. Tese (Doutorado em Educação) - Programa de Pós-Graduação em Educação, Faculdade de Educação, Universidade Federal do Rio Grande do Sul, RS, 2001.

BUJES, Maria Isabel Edelweiss. A invenção do eu infantil: dispositivos pedagógicos em ação. Rev. Bras. Educ., Rio de Janeiro, n. 21, p. 17-39, dez. 2002. Disponível em http://www.scielo.br/scielo.php?script=sci_arttext\&pid=S1413-24782002000300003\&lng=en\&nrm=iso. Acesso em 20 jun. 2019.

BUJES, Maria Isabel Edelweiss. Artes de governar a infância: linguagem e naturalização da criança na abordagem de educação infantil da Reggio Emília. Educ. rev., Belo Horizonte, n. 48, p. 101-123, dez. 2008. Disponível em http://www.scielo.br/scielo.php?script=sci_arttext\&pid=S0102$46982008000200006 \& \operatorname{lng}=e n \& n r m=i s o$. Acesso em 20 jun. 2019.

CORREAA, Mirele. O que pode um corpo na escola? Uma cartografia das potencialidades do corpo em espaço de escolarização. 2017. Dissertação (Mestrado em Educação) - Programa de Pós-Graduação em Educação, Centro de Ciências de Educação, Artes e Letras, Universidade Regional de Blumenau, SC, 2017.

DARDOT, Pierre; LAVAL, Christian. La nouvelle raison du monde: Essai sur la société néolibérale. Paris: La Découverte, 2009.

FADERMAN, Lilian. Surpassing the love of men: Romantic Friendship and Love Between Women from the Renaissance to the Present. New York, United States: Perennial, 2001.

FOUCAULT, Michel. Surveiller et punir. Paris: Éditions Gallimard, 1975.

FOUCAULT, Michel. Histoire de la sexualité 1: la volonté de savoir. Paris: Éditions Gallimard, 1976.

FOUCAULT, Michel. Les Anormaux: cours au Collège de France (1974-1975). Paris: Éditions Gallimard; Éditions Seuil, 1999.

FOUCAULT, Michel. Sécurité, territoire, population: cours au Collège de France (1977-1978). Paris: Éditions Gallimard; Éditions Seuil, 2004a.

FOUCAULT, Michel. La naissance de la biopolitique: cours au Collège de France (1978-1979). Paris: Éditions Gallimard; Éditions Seuil, 2004b.

FRAISSE, Jean-Claude. Philia : la notion d'amitié dans la philosophie antique. Paris: Librairie Philosophique J. Vrin, 2016.

GADELHA, Sylvio de Souza. Governamentalidade neoliberal e instituição de uma infância empreendedora. In. KOHAN, Walter Omar. Devir-criança da filosofia: infância da educação. Belo Horizonte: Autêntica Editora, 2010. p. 123-138.

GADELHA, Sylvio de Souza. Empresariamento da sociedade e governo da infância pobre. In. RESENDE, Haroldo (org.). Michel Foucault: o governo das infâncias. Belo Horizonte: Autêntica Editora, 2015. p. 345366.

HARTUP, Willard W.; MOORE, Shirley G. Early Peer Relations: Developmental

Significance and Prognostic Implications. Early Childhood Research Quarterly, n. 5, p. 1-17, mar. 1990.

HARTUP, Willard W. Having friends, making friends and keeping friends: Relationships as Educational Contexts. ERIC Digest, [s. 1.], 1992. Disponível em: https://eric.ed.gov/?id=ED345854. Acesso em: 05 abr. 2018.

HEYWOOD, Colin. Uma história da infância: Da Idade Média à Época Contemporânea no Ocidente. Porto Alegre: Artmed, 2004 
KATZ, Lilian G.; MCCLELLAN, Diane E. The teacher's role in the social development of young children. Urbana, IL: ERIC/EECE, 1991.

KOHAN, Walter Omar. Infância: Entre Educação e Filosofia. Belo Horizonte: Autêntica Editora, 2005.

KONSTAN, David. Friendship in the classical world. New York, United States: Cambridge University Press, 1997.

LADD, Gary W. Having Friends, Keeping Friends, Making Friends and Being Liked by

Peers in the Classroom: Predictors of Children's Early School Adjustment?. Child

Development, n. 61, p. 1081-110, aug., 1990.

LARROSA, Jorge. Tremores: escritos sobre experiência. 2. ed. Belo Horizonte: Autêntica Editora, 2016.

LARROSA, Jorge. Esperando não se sabe o quê: sobre o ofício de professor. 1. ed. Belo Horizonte: Autêntica Editora, 2018.

LAVAL, Christian. A Escola não é uma empresa: o neo-liberalismo em ataque ao ensino público. Londrina: Editora Planta, 2004.

LES QUATRE Cents Coups. Direção: François Truffaut. Produção: Les Films du Carrosse;

SEDIF Productions. France, 1959. 99 min. Son., P/B

LOPONTE, Luciana Gruppelli. Amizades: o doce sabor dos outros na docência. Cad. Pesqui., São Paulo, v.39, n.138, p.919-938, dez. 2009.

LOS OLVIDADOS. Direção: Luis Buñuel. Produção: Óscar Dancigers; Sergio Kogan; Jaime A. Menasce. Mexico, 1950. 88 min. Son., P/B.

LUQUE PARRA, Diego Jesús; LUQUE ROJAS, María Jesús. Relaciones de amistad y solidaridad en el aula: Un acercamiento psicoeducativo a la discapacidad en un marco inclusivo. Revista Mexicana de Investigación Educativa, v.20, n.65, p.369-392, jun. 2015.

MASSCHELEIN, Jan; SIMONS, Maarten. Defensa de la Escula: una cuestión pública. Buenos Aires: Miño y Dávila Editores, 2014.

MIZOGUCHI, Daniel Hausen. Amizades contemporâneas: inconclusas modulações de nós. Porto Alegre: Sulina; Editora da UFRGS, 2016.

MUÑOZ, Nuria Malajovich. Do amor à amizade na psicose: contribuições da psicanálise ao campo da saúde mental. Rev. latinoam. psicopatol. fundam., São Paulo, v.13, n.1, p. 87-101, mar. 2010.

NARODOWSKI, Mariano. Infância e Poder: a conformação da Pedagogia Moderna. Bragança Paulista: Editora da Universidade São Francisco, 2001.

Ó, Jorge Ramos do. O governo de si mesmo: modernidade pedagógica e encenações disciplinares do aluno liceal (último quartel do século XIX - meados do século XX). Lisboa: Educa, 2003.

ORTEGA, Francisco. Genealogias da amizade. Rio de Janeiro: Iluminuras, 2002.

PLATÃO. Lysis; Symposium; Gorgias. London: Harvard University Press: 1925.

RESENDE, Haroldo (org.). Michel Foucault: o governo das infâncias. Belo Horizonte: Autêntica Editora, 2015. p. 259-280.

ROUSSEAU, Jean-Jacques. La nouvelle Héloüse. Paris: Librairie de Firmin Didot Frères, 1843.

ROUSSEAU, Jean-Jacques. Émile, ou de l'éducation. Paris: Éditions Flammarion, 1966.

SAMPAIO, Helena Almeida e Silva. Olhei uma infância a desabar sobre uma criança: 
fotografei o sobre. 2019. Dissertação (Mestrado em Educação) - Programa de Pós-Graduação em Educação, Centro de Ciências de Educação, Artes e Letras, Universidade Regional de Blumenau, SC, 2019. SCHÉRER, René. Enfantines. Paris: Economica, 2002.

SCHÉRER, René. Émile perverti: ou des rapportes entre l'éducation et la sexualité. Paris: Éditions du Rocher, 2006.

SOUZA, Eloisio Moulin de; GARCIA, Agnaldo. Amigos, amigos: negócios à parte? Revista de Administração, [S.I.], v. 43, n. 3, p. 238-249, Sep. 2008.

SOUZA, Luciana Karine de; SEDIYAMA, Cristina Yumi Nogueira. Amizades internacionais: panorama da literatura empírica e um estudo descritivo. Barbaroi, Santa Cruz do Sul, n.36, p.6-28, jun. 2012.

VESENTINI, J. William; MARTINS, Dora; PÉCORA, Marlene. Ápis: história. São Paulo: Ática, 2011. ZÉRO de conduite : Jeunes diables au collège. Direção: Jean Vigo. Produção: Jean Vigo. France, 1933. 42 $\min$. Son., P/B.

Recebido em: 30/04/2020.

Revisões Requeridas em: 05/08/2020.

Aceito em: 14/08/2020.

Notas

\footnotetext{
i Universidade do Estado de Santa Catarina - UDESC. E-mail: luizg.augs@gmail.com Santa Catarina. ORCID: https://orcid.org/0000-0003-3136-9890

ii Universidade do Estado de Santa Catarina - UDESC. E-mail: anamariapreve@gmail.com Santa Catarina. ORCID: https://orcid.org/0000-0002-6423-4194
} 